\title{
Sexual abuse and suicidality: gender differences in a large community sample of adolescents ${ }^{\text {th }}$
}

\author{
Graham Martin $^{\mathrm{a}, *}$, Helen A. Bergen ${ }^{\mathrm{a}}$, Angela S. Richardson ${ }^{\mathrm{a}}$, \\ Leigh Roeger $^{\mathrm{b}}$, Stephen Allison ${ }^{\mathrm{b}}$ \\ ${ }^{a}$ Department of Psychiatry, The University of Queensland, Brisbane, Qld., Australia \\ ${ }^{\mathrm{b}}$ Southern Child and Adolescent Mental Health Service, Flinders Medical Centre, Adelaide, SA, Australia
}

Received 10 December 2002; received in revised form 28 July 2003; accepted 10 August 2003

\begin{abstract}
Objective: A cross-sectional study of gender specific relationships between self-reported child sexual abuse and suicidality in a community sample of adolescents.

Method: Students aged 14 years on average $(N=2,485)$ from 27 schools in South Australia completed a questionnaire including items on sexual abuse and suicidality, and measures of depression (Centre for Epidemiological Studies Depression Scale), hopelessness (Beck Hopelessness Scale), and family functioning (McMaster Family Assessment Device General Functioning Subscale). Data analysis included logistic regression.

Results: In boys, self-report sexual abuse is strongly and independently associated with suicidal thoughts, plans, threats, deliberate self-injury, and suicide attempts, after controlling for current levels of depression, hopelessness, and family dysfunction. In girls, the relationship between sexual abuse and suicidality is mediated fully by depression, hopelessness, and family dysfunction. Girls who report current high distress about sexual abuse, however, have a threefold increased risk of suicidal thoughts and plans, compared to non-abused girls. Boys who report current high distress about sexual abuse have 10-fold increased risk for suicidal plans and threats, and 15-fold increased risk for suicide attempts, compared to non-abused boys. Fifty-five percent $(n=15)$ of sexually abused boys attempted suicide versus $29 \%(n=17)$ girls.
\end{abstract}

Conclusions: A history of sexual abuse should alert clinicians, professionals and carers in contact with adolescents, to greatly increased risks of suicidal behavior and attempts in boys, even in the absence of depression and hopelessness.

\footnotetext{
is Financial support was provided by the South Australian Health Commission.

* Corresponding author address: Child and Adolescent Psychiatry, The University of Queensland, Mental Health Center, K Floor, Royal Brisbane Hospital, Herston, Qld 4029, Australia
} 
Distress following sexual abuse, along with depression and hopelessness indicate increased risk of suicidal behavior in girls, as well as boys.

(c) 2004 Published by Elsevier Ltd.

Keywords: Child sexual abuse; Suicidality; Adolescents; Gender differences

\section{Introduction}

Child sexual abuse (CSA) is known to have serious adverse effects on the psychosocial development of children and young adolescents, effects extending into adulthood (Beitchman, Zucker, Hood, daCosta, \& Akman, 1991; Mullen, King, \& Tonge, 2000; Tyler, 2002). Recent research argues for a multifaceted model of traumatisation rather than a specific sexual abuse syndrome (Paolucci, Genuis, \& Violato, 2001), and CSA may be best conceptualized as a non-specific risk factor for adverse adult outcomes (Romans, Martin, $\&$ Mullen, 1997). Although abuse of all forms is more frequent in those from disturbed and disrupted family backgrounds, not all apparent associations between abuse and adult problems are accounted for by childhood disadvantage (Mullen, Martin, Anderson, Romans, \& Herbison, 1996). Stevenson (1999) suggests abused children are at risk of long-term psychological sequelae related to the abuse itself, not merely as a consequence of other associated background factors. Prospective studies of abused children (Calam, Horne, Glasgow, \& Cox, 1998), longitudinal studies of adolescents and young adults (Brown, Cohen, Johnson, \& Smailes, 1999; Silverman, Reinherz, \& Giaconia, 1996), retrospective studies of adults (Barker Collo, 2001) and adult twins (Nelson et al., 2002) all indicate significant disturbance in the psychological functioning of survivors of abuse.

One particular outcome of CSA is increased suicidality (Beckinsale, Martin, \& Clark, 1999; Bensley, Van Eenwyk, Spieker, \& Schoder, 1999; Martin, 1996). Beautrais (2000) reviewed risk factors for youth suicide and found mental disorders and adverse childhood experiences to be strong risk factors, with odds ratios for suicide attempt ranging from 1.5 to 11.8 for sexually abused youth, compared to non-abused. In a large US-based survey ( $n=5,877,15-54$ years old), Molnar, Berkman, and Buka (2001) found a strong association between CSA and suicidal behavior mediated by psychopathology, with the odds of suicide attempt in sexually abused women 2-4 times that of non-abused women, and in men 4-11 times, controlling for other adversities.

The nature of CSA is an important factor in determining outcomes, with more extreme forms of abuse involving force or penetration associated with more harmful long-lasting effects (Tyler, 2002) and increased distress (Pillay \& Schoubben Hesk, 2001). Worse CSA and increased distress also increase severity of suicidal behavior (Fergusson, Lynskey, \& Horwood, 1996; Lipschitz et al., 1999).

Gender differences may also be important. The incidence of sexual abuse is lower in boys than girls, and the community believes that sexual abuse of boys is less serious and less harmful (Broussard, Wagner, \& Kazelskis, 1991; Smith, Fromuth, \& Morris, 1997). Of importance, this may adversely influence decision-making with regard to their care and protection. In fact, the experience carries more consequences for boys than for girls in regard to alcohol/drug use, aggressive behavior, and truancy as well as suicidality (Garnefski \& Arends, 1998). Gender differences in the interplay between psychological functioning and suicidality of young adolescents have been found by others (Allison, Roeger, Martin, \& Keeves, 2001; Lewinsohn, Rohde, Seeley, \& Baldwin, 2001; Rich, Kirkpatrick Smith, Bonner, \& Jans, 1992), and further work to clarify the area has been recommended (Mazza \& Reynolds, 1998). 
Many existing studies in the area of sexual abuse are retrospective reports from adults, providing insight long after the event (abuse generally in the pre-pubertal period, 8-12 years) (Goldman \& Padayachi, 1997). Much valuable contextual and perceptual data is missing or forgotten. Greater knowledge is required at a stage where early intervention with depression and suicidal behavior can provide the opportunity for effective prevention of the possible outcome of suicide. Reviews of CSA studies suggest that future work should use appropriate contrast groups (i.e., normal populations) at identified chronological and developmental age periods (Paolucci et al., 2001). This also makes sense given that some youth suicides occur outside "psychiatric populations," suggesting studies of community samples are needed to provide information about risk factors beyond the boundaries of psychopathology.

Measures of suicidality in children and adolescents can be influenced by the instrument, retrospection, and who does the reporting (Klimes Dougan, 1998), and multiple method assessments including clinical judgment and self-report are most likely to indicate actual risk (Prinstein, Nock, Spirito, \& Grapentine, 2001). Despite this, self-report measures are valuable tools, in that they tap current and contextually relevant emotional states of the respondent in a non-judgmental and non-threatening manner.

This paper contributes to the literature in a number of important ways. First we attempt to clarify gender differences in response to CSA, to address community perceptions that it is less serious for boys. Second, we use a large community sample of young adolescents rather than a clinical or adult population. Third, we highlight the association between CSA and suicidality. Specifically, gender differences in associations between sexual abuse and suicidal behavior (comprising suicidal ideation, plans, threats, and deliberate self-injury [DSI], and suicide attempts) are the prime focus of the study. Depression, hopelessness, and family functioning, also known to be associated with sexual abuse and suicidality (Bergen, Martin, Richardson, Allison, \& Roeger, 2003), are controlled for in logistic regression analyses.

\section{Method}

\section{Participants}

This work derives from the Early Detection of Emotional Disorders program, a 3-year repeated measures longitudinal study of young adolescents, focusing on early detection of suicidal behaviors, and risk and protective factors implicated in later suicide. Following approval from the South Australian Department of Education and Children's Services, and the Flinders Medical Centre Ethics Committee on Clinical Investigations, 25 government schools in the mental health service catchment area (approximately one-third of South Australia's government secondary school population) were invited to participate; 17 principals and parent-teacher councils agreed. Ten independent schools were added to reflect the population mix. The total sample comprised both rural and suburban schools in lower to upper middle socio-economic areas. Participants were surveyed yearly in three waves: at time one, they were in Year 8 high school (mean age 13 years); at time two, Year 9 (mean age 14 years); and at time three, Year 10 (mean age 15 years). Data used in this cross-sectional analysis, previously unreported, is drawn from the second wave.

\section{Procedure}

Following parental permission, 2,485 students were surveyed, an overall response rate of approximately $85 \%$. Students were informed participation was voluntary, and non-participation would have no 
adverse consequences. Questionnaires were completed in class time under supervision of teachers, and responses placed in sealed containers to maintain anonymity. A group debriefing session followed, a school counsellor being available for any student showing distress.

\section{Measures}

Items of interest reported here form part of a larger composite questionnaire (Martin, Allison, et al., 1995; Martin, Rozanes, Pearce, \& Allison, 1995). Socio-demographic information includes school, gender, age, country of birth, main language spoken at home, Aboriginal or Torres Strait origin.

1. Depressive Symptomatology was measured with the Centre for Epidemiological Studies Depression Scale (CES-D), a self-report 20-item instrument recommended for use with community samples of adults (Radloff, 1977) and adolescents (Roberts, Andrews, Lewinsohn, \& Hops, 1990; Radloff, 1991). Respondents rate frequency of depressive symptoms in the past week on a 4-point scale from 0 (rarely or never), 1 (some or a little of the time), 2 (occasionally or a moderate amount of the time), to 3 (most or all of the time). A cut-off score of 16 was used to identify those "depressed" (Radloff, 1977), from which a dichotomous variable was recoded for use in $\chi^{2}$ analyses.

2. Hopelessness was measured with the Beck Hopelessness Scale (Beck, Weissman, Lester, \& Trexler, 1974), a 20-item true/false self-report instrument assessing negative expectations about the future. The scale has good internal consistency and validity with clinician's ratings, and has been used extensively with adolescents (Gibb et al., 2001).

3. Global family functioning was measured with the 12-item Family Assessment Device General Functioning subscale which measures agreement using a 4-point scale for each item. Overall mean item scores range from 1.0 to 4.0 , with higher scores indicating greater family pathology. The scale has good reliability, internal consistency, and validity in distinguishing clinical from non-clinical families (Byles, Byrne, Boyle, \& Offord, 1988). Family dysfunction measured on the FAD-GF is associated with sexual abuse (Martin, 1996), severe depression and suicidality (Martin, Rozanes, Pearce, \& Allison, 1995).

4. Sexual abuse was assessed with one question "Have you ever been sexually abused" with a "yes/no" response. Two further questions were posed. The first, "If yes, then by whom?" had a choice of responses "a friend, a family member, someone else known to you, a stranger." The second, "How distressed do you feel about this now?" had response choices on a 7-point Likert scale of 0 (not at all distressed), to 6 (extremely distressed). A 3-category variable "distress" was coded with non-abused respondents coded 0 , sexually abused respondents reporting low levels of distress (scores $0-2$ ) coded 1 , and sexually abused respondents reporting high levels of distress (scores 3-6) coded 2.

5. Assessment of suicidality was based on the concept of a "spectrum of suicidality" (Pfeffer et al., 1991), and the work of Pearce and Martin (1994). Items included in this study were: "Have you ever ... thought about killing yourself"; “... made plans to kill yourself without carrying them out?"; "made threats to others that you will kill yourself"; “. . deliberately tried to hurt yourself?"; and "... tried to kill yourself?" Response choices are "never," and "yes" with six options of when it occurred, from "last month," to "more than 12 months ago." We assumed that respondents distinguished "deliberately hurting themself" (DSI) from "trying to kill themself" (suicide attempt). For this study, positive responses were collapsed to provide yes/no categorical data. Following a "yes" response to an 
attempt, students were asked whether they had needed emergency medical treatment or hospitalization, two ways to assess seriousness of the attempt.

\section{Data analysis}

Analysis was performed with SPSS v11, using descriptive statistics and $\chi^{2}$ tests to investigate univariate relationships, and logistic regression to investigate significant multivariate relationships. Two-way interactions between gender and CSA were significant, thus separate logistic regression analyses were conducted for boys and girls to highlight the nature of differences between boys' and girls' responses. With regard to logistic regression analyses, Farrington and Loeber (2000) suggest dichotomization of the dependent variable does not necessarily cause a decrease in measured strength of association between variables, and produces easily interpretable and understandable findings in terms of odds ratios, compared to ordinary least squares multiple regression and the product moment correlation $r$. This suited our data well, with the naturally dichotomous variables of suicidal ideas, plans, threats, DSI and attempts.

Our analyses focused on investigating independent contributions of "sexual abuse" and associated "distress" to suicidality, controlling for the most commonly associated internalizing risk factors of "depression" and hopelessness. Socio-demographic and parenting style variables were screened for significance; none contributed independent of our "family functioning" measure (the FAD-GF). Thus "depression," hopelessness, and family functioning were included into regression models as co-variates. (Individual contributions, although interesting, are not reported here due to space constraints.) Co-variates were used in their continuous (rather than dichotomous) form, to ensure that maximum variability in the data was included in the regression models.

Examination of tolerance values and variance proportions for all variables indicated no multi-collinearity (Tabachnick \& Fidell, 2001), and the high ratio of number of cases to independent variables indicated it was safe to undertake logistic regression tests (Garson, 2002).

\section{Results}

Approximately $85-87 \%$ of the 2,485 students fully completed each section of the questionnaire relevant to this study. Descriptive statistics are reported in Table 1.

Reported experience of sexual abuse was more prevalent amongst girls (girls $5.4 \%$ vs. boys $2.0 \%$ ). Current distress from past sexual abuse was not associated with the identity of the abuser, but was related to depressive symptomatology $\left[\chi^{2}(1)=8.50, p<.05\right]$ with $86.2 \%$ of those reporting high distress levels (scores 3-6) following abuse classified here as "depressed" (Radloff, 1977).

Sexually abused adolescents were much more likely to report having had "thoughts about killing themselves," [73\% abused, 25\% non-abused, $\left.\chi^{2}(1)=96.56, p<.001\right]$; to have "made plans," [55\% abused, $12 \%$ non-abused, $\left.\chi^{2}(1)=131.44, p<.001\right]$; to have "made threats" [45\% abused, 9\% non-abused, $\left.\chi^{2}(1)=113.5, p<.001\right]$; to have "deliberately hurt themselves" [54\% abused, $17 \%$ non-abused, $\left.\chi^{2}(1)=75.10, p<.001\right]$; and to claim attempt(s) to kill themselves, [24\% abused, $5 \%$ non-abused, $\left.\chi^{2}(1)=171.86, p<.001\right]$.

In addition, frequency and severity of suicidal behavior appear to be greater amongst sexually abused adolescents. When asked how often they hurt themselves deliberately, 30\% of abused versus $5 \%$ of non-abused claimed five or more injuries $\left[\chi^{2}(1)=49.76, p<.001\right]$. Regarding attempts, $32 \%$ of abused 
Table 1

Descriptive statistics of community sample of adolescents aged 14 years

\begin{tabular}{|c|c|c|c|}
\hline & Boys & Girls & Total \\
\hline Total, $N(\%)$ & $1369(55.5 \%)$ & $1106(44.5 \%)$ & 2485 \\
\hline \multicolumn{4}{|l|}{ Sexual abuse } \\
\hline Yes, $n(\%)$ & $27(2.0 \%)$ & $59(5.4 \%)$ & $87(3.6 \%)$ \\
\hline Abused by family member & 6 & 14 & 20 \\
\hline High distress (scores 3-6) & 19 & 40 & 59 \\
\hline Depressive Symptomatology, $n$ & 1283 & 1053 & 2343 \\
\hline CES-D mean $(S D)$ & $10.68(8.72)$ & $13.41(10.74)$ & $11.91(9.77)$ \\
\hline 'Depressed' scores > 16 & $281(21.9 \%)$ & $355(33.7 \%)$ & $638(27.2 \%)$ \\
\hline Hopelessness, $n$ & 1261 & 1006 & 2274 \\
\hline Beck mean $(S D)$ & $3.54(3.83)$ & $3.52(3.82)$ & $3.54(3.84)$ \\
\hline 'Hopeless' scores $>$ mean $+S D$ & $167(13.2 \%)$ & $112(11.1 \%)$ & $282(12.4 \%)$ \\
\hline Global family functioning, $n$ & 1327 & 1082 & 2417 \\
\hline FAD-GF mean $(S D)$ & $1.87(.47)$ & $1.85(.52)$ & $1.86(.49)$ \\
\hline \multicolumn{4}{|l|}{ Suicidality, $n(\%)$} \\
\hline Ideation: yes & $292(21.8 \%)$ & $364(33.6 \%)$ & $659(27.1 \%)$ \\
\hline Plans: yes & $149(11.3 \%)$ & $176(16.4 \%)$ & $328(13.7 \%)$ \\
\hline Threats: yes & $109(8.2 \%)$ & $142(13.1 \%)$ & $253(10.5 \%)$ \\
\hline Deliberate self-injury: yes & $231(17.5 \%)$ & $208(19.3 \%)$ & $442(18.4 \%)$ \\
\hline Attempts: yes & $59(4.5 \%)$ & $78(7.3 \%)$ & $139(5.8 \%)$ \\
\hline Emergency treatment & 12 & 13 & 25 \\
\hline Hospital admission & 13 & 7 & 20 \\
\hline
\end{tabular}

Note. Total includes 10 cases with missing gender.

versus $2 \%$ non-abused had tried to kill themselves five or more times $\left[\chi^{2}(1)=30.13, p<.001\right]$. Further, $36 \%$ of abused versus $8 \%$ of non-abused were admitted to hospital $\left[\chi^{2}(1)=14.95, p<.001\right]$, suggesting a medically serious attempt. Gender specific analyses reveal that 55\% $(n=15)$ of sexually abused boys versus $3.5 \%(n=44)$ of non-abused boys reported attempted suicide $\left[\chi^{2}(1)=164.79, p<.001\right]$, and $29 \%(n=17)$ of sexually abused girls versus $6 \%(n=60)$ of non-abused girls reported attempted suicide $\left[\chi^{2}(1)=44.39, p<.001\right]$.

Adolescents reporting sexual abuse scored higher [mean $=23.86, S D=13.73$ ] than non-abused [mean $=11.47, S D=9.3$ ] on the CES-D depression scale [Mann-Whitney $U=38,551, Z=-8.243$, $p<.001]$. Sexually abused adolescents also scored higher [mean $=6.68, S D=5.92]$ than non-abused $[$ mean $=3.42, S D=3.7$ ] on the Beck Hopelessness Scale [Mann-Whitney $U=56,692.5, Z=-5.314$, $p<.001]$.

Logistic regression was used to investigate the contribution of sexual abuse and associated distress (as independent variable predictors) to suicidal ideas, plans, threats, DSI, and suicide attempts (each as a dependent outcome variable). Separate analyses were conducted for the 2-category independent variable "sexual abuse" (yes; no), and for the 3-category independent variable "distress" categorizing those reporting sexual abuse according to level of distress, with a referent category of no abuse (none; abuse and low distress; abuse and high distress). Separate analyses were performed for each of the five 
Table 2

Logistic Regression Models for suicidal outcomes associated with sexual abuse and distress, unadjusted and adjusted for depressive symptomatology, hopelessness and family functioning, in boys

\begin{tabular}{|c|c|c|}
\hline & \multicolumn{2}{|l|}{ Odds ratio $(95 \% \mathrm{CI})^{\mathrm{a}}$} \\
\hline & Unadjusted & Adjusted \\
\hline \multicolumn{3}{|l|}{ Suicidal ideas } \\
\hline Sexual abuse & $11.9(4.3-33.0)^{* * *}$ & $5.0(1.5-16.8)^{* *}$ \\
\hline Distress-low & ns & ns \\
\hline Distress-high & $15.8(4.4-56.5)^{* * *}$ & $7.4(1.7-31.8)^{* *}$ \\
\hline \multicolumn{3}{|l|}{ Suicidal plans } \\
\hline Sexual abuse & $21.3(8.0-56.6)^{* * *}$ & $10.6(3.5-32.7)^{* * *}$ \\
\hline Distress-low & $13.7(2.3-82.9)^{* *}$ & ns \\
\hline Distress-high & $25.1(7.9-80.3)^{* * *}$ & $13.3(3.6-49.6)^{* * *}$ \\
\hline \multicolumn{3}{|l|}{ Suicidal threats } \\
\hline Sexual abuse & $19.4(7.7-48.7)^{* * *}$ & $10.9(3.9-30.4)^{* * *}$ \\
\hline Distress-low & $19.4(3.2-117.4)^{* * *}$ & $10.4(1.4-77.3)^{*}$ \\
\hline Distress—high & $19.4(6.7-55.7)^{* * *}$ & $11.1(3.4-35.7)^{* * *}$ \\
\hline \multicolumn{3}{|c|}{ Deliberate self-injury } \\
\hline Sexual abuse & $10.3(4.0-26.0)^{* * *}$ & $4.3(1.5-12.6)^{* *}$ \\
\hline Distress-low & $8.3(1.4-50.0)^{*}$ & ns \\
\hline Distress-high & $11.1(3.7-32.7)^{* * *}$ & $4.8(1.4-16.6)^{*}$ \\
\hline \multicolumn{3}{|l|}{ Suicide attempts } \\
\hline Sexual abuse & $30.8(12.0-78.6)^{* * *}$ & $15.0(4.7-47.9)^{* * *}$ \\
\hline Distress-low & $20.5(3.3-126.6)^{* * *}$ & ns \\
\hline Distress-high & $35.2(12.1-102.3)^{* * *}$ & $18.7(5.0-70.1)^{* * *}$ \\
\hline
\end{tabular}

Note. Separate Direct Logistic Regression Models: (i) predictor sexual abuse (yes); and (ii) predictor distress (low scores 0-2; high scores 3-6). Both predictors have referent category: no sexual abuse. ${ }^{* * *} p<.001$ except ${ }^{* *} p<.01,{ }^{*} p<.05$, ns $p>.05$.

${ }^{a}$ Unadjusted, and adjusted for continuous co-variates: depression, hopelessness and family functioning.

suicidal variables as the outcome variable. Thus, 10 analyses were performed in all for both boys and girls.

Each analysis was conducted in two steps using the direct entry method to allow evaluation of the unique contribution made by each predictor beyond that of other predictors. First, the independent variable predictor (either "sexual abuse" or "distress") was entered into the regression to give a Wald statistic, significance level, and unadjusted odds ratio. Second, continuous variables "depression," hopelessness and global family functioning were entered to adjust for confounding effects, giving an adjusted odds ratio. This adjusted odds ratio represents the estimated increased risk (in prediction of the outcome) for a one unit increase in value of the independent variable predictor, after the contributions by all other co-variates are taken into account. (The term predictor is common usage in discussions of logistic regression and here does not imply causality) (Tabachnick \& Fidell, 2001).

Results for separate regression models using predictors (1) "sexual abuse" and (2) "distress" are presented together in Table 2 (boys) and Table 3 (girls).

A test of the full model with predictor sexual abuse and three co-variates "depression," hopelessness, and family functioning was statistically reliable $(p<.001)$ for all suicidal outcome variables. For example, 
Table 3

Logistic Regression Models for suicidal outcomes associated with sexual abuse and distress, unadjusted and adjusted for depressive symptomatology, hopelessness and family functioning, in girls

\begin{tabular}{|c|c|c|}
\hline & \multicolumn{2}{|c|}{ Odds ratio $(95 \% \mathrm{CI})^{\mathrm{a}}$} \\
\hline & Unadjusted & Adjusted \\
\hline \multicolumn{3}{|l|}{ Suicidal ideas } \\
\hline Sexual abuse & $4.6(2.5-8.5)^{* * *}$ & ns \\
\hline Distress-low & ns & ns \\
\hline Distress-high & $11.8(4.5-30.8)^{* * *}$ & $3.3(1.1-10.2)^{*}$ \\
\hline \multicolumn{3}{|l|}{ Suicidal plans } \\
\hline Sexual abuse & $4.4(2.5-7.9)^{* * *}$ & ns \\
\hline Distress-low & ns & ns \\
\hline Distress-high & $9.0(4.4-18.5)^{* * *}$ & $2.7(1.2-6.3)^{*}$ \\
\hline \multicolumn{3}{|l|}{ Suicidal threats } \\
\hline Sexual abuse & $4.6(2.5-8.4)^{* * *}$ & ns \\
\hline Distress-low & ns & ns \\
\hline Distress-high & $7.3(3.6-14.9)^{* * *}$ & ns \\
\hline \multicolumn{3}{|c|}{ Deliberate self-injury } \\
\hline Sexual abuse & $3.3(1.8-5.9)^{* * *}$ & ns \\
\hline Distress-low & ns & ns \\
\hline Distress-high & $5.1(2.5-10.2)^{* * *}$ & ns \\
\hline \multicolumn{3}{|l|}{ Suicide attempts } \\
\hline Sexual abuse & $5.1(2.5-10.4)^{* * *}$ & ns \\
\hline Distress-low & ns & ns \\
\hline Distress-high & $7.0(3.2-15.5)^{* * *}$ & ns \\
\hline
\end{tabular}

Note. Separate Direct Logistic Regression Models: (i) predictor sexual abuse (yes); and (ii) predictor distress (low scores 0-2; high scores 3-6). Both predictors have referent category: no sexual abuse. ${ }^{* * *} p<.001,{ }^{* *} p<.01,{ }^{*} p<.05$, ns $p>.05$.

${ }^{a}$ Unadjusted, and adjusted for continuous co-variates: depression, hopelessness and family functioning.

model $\chi^{2}$ values for suicidal ideas were boys $\chi^{2}(4)=202.43$ and girls $\chi^{2}(4)=290.04$. Nagelkerke $R^{2}$ values ranged from .17 (threats) to .34 (attempts) for boys; and .22 (DSI) to .27 (ideas) for girls. As expected, similar values are found for models using "distress" rather than "sexual abuse" as the predictor.

For boys, Wald statistic and unadjusted odds ratios for "sexual abuse" onto all five suicide variables are large and significant $(p<.001)$, indicating reliable association with the regression outcome. Following adjustment by inclusion of "depression," hopelessness, and family functioning, Wald values reduce and odds ratios are halved, though remaining large (from 4- to 15-fold) and significant for plans, threats and attempts $(p<.001)$, and for ideas and DSI $(p<.01)$.

Further inspection of Table 2 reveals that high levels of distress following sexual abuse are significantly associated with increased risks of suicidal outcomes in sexually abused boys, compared to non-abused. In contrast, for sexually abused boys reporting low levels of distress, increased risks are significant only for suicide threats $(p<.05)$.

For girls, unadjusted odds ratios for sexual abuse onto all five suicide variables are smaller than for boys, and after adjustment for depression, hopelessness, and family functioning are not significant. High levels of distress, however, are significantly associated with suicidal ideas and plans $(p<.05)$. 


\section{Discussion}

The findings of this cross-sectional study of a large community sample of adolescents indicate that the experience of sexual abuse is strongly associated with suicidal ideation and suicidal behavior comprising plans, threats, deliberate self-injury and attempts. Striking gender differences are apparent. In girls, although an association between sexual abuse and suicidality is evident initially, depressive symptomatology, hopelessness, and family functioning appear to mediate the relationship. In boys, after controlling for current levels of depressive symptomatology, hopelessness, and family functioning, a 10-fold increased risk of making suicidal plans and threats, and a 15-fold increased risk of attempting suicide remain for sexually abused compared to non-abused boys.

Further, when investigating current distress associated with reported experience of sexual abuse, high levels of distress are more strongly associated with suicidal ideas and plans in both boys (7- to 13-fold increased risk) and girls (approximately threefold increased risk at $p<.05$ ), and with suicide attempts in boys with an increased risk of 18 -fold $(\mathrm{OR}=18.7,95 \% \mathrm{CI}=5.0-70.1, p<.001)$, after adjusting for co-variates. In boys, both low and high levels of distress are associated with a 10-fold increased risk of suicidal threats (at $p<.05$ and $p<.001$ ), though only high levels of distress contribute to deliberate self-injury $(p<.05)$.

Prevalence rates of abuse in this community study are low compared to retrospective reports of Australian adults, and by comparison to previous work using a smaller sample of 15-year olds from one school (Martin, 1996). They are consistent, however, with lower rates of self-report by children, and with serious contact abuse (Goldman \& Padayachi, 1997; Mullen et al., 2000). Although the number of independent variables is low compared to the " 1 independent for each 10 cases rule," and therefore satisfactory (Garson, 2002, p. 19), statistical power is reduced. Care should therefore be exercised in over-interpreting the large gender differences, as the wide spread in $95 \%$ confidence intervals of the odds ratios for boys indicates large statistical errors, possibly caused by the small sample size. However, a trend is clear with $55 \%(n=15)$ of sexually abused boys reporting suicide attempts versus $29 \%(n=17)$ of sexually abused girls. Our tentative interpretation supports existing evidence that boys' responses to sexual abuse may be more severe than girls (Garnefski \& Arends, 1998; Molnar, Berkman, \& Buka, 2001).

This study is cross-sectional, and causal inferences cannot therefore be made. However, the strong association between sexual abuse and suicide attempts, even after controlling for depressive symptomatology, hopelessness and family functioning, is in agreement with other studies of young adults (Brown et al., 1999). The independent, "direct" correlation of sexual abuse with suicide attempts in boys may be through mechanisms not included in our model, which focuses on internalizing clinical issues like depression and hopelessness. Externalizing clinical issues such as risk taking, delinquency and substance abuse may be involved in mediating these relationships. This is the subject of future work.

The use of self-report measures in this study of community adolescents is both a strength and a possible weakness. The term "sexual abuse" was not defined in the questionnaire, and thus responses relate to adolescent perceptions of what constitutes this behavior. With increased publicity and community awareness of sexual abuse issues in the last decade, it may be assumed that responses of these 14-year olds, although unsubstantiated, are a valid and acceptable measure. High school students' perceptions of sexual harassment, for instance, are more lenient than currently accepted definitions (Corbett, Gentry, \& Pearson, 1993; Loredo, Reid, \& Deaux, 1995). It must also be noted that this study lacks detail regarding the exact nature and severity of sexual abuse, as questions were necessarily restricted by the need to gain 
parental and educational authority approval, a limitation noted by others (Bensley et al., 1999). However, our assessment of distress following abuse may be taken as an indirect measure of severity (Pillay \& Schoubben Hesk, 2001). Further, our finding that higher levels of distress following sexual abuse are more strongly associated with suicidal outcomes than lower levels of distress, gives confidence in the reliability of adolescent responses.

In conclusion, in the clinical context with suicidal young adolescents we recommend that practitioners take an abuse history routinely, and be cognisant of increased risk for suicidal behavior and suicide attempts in sexually abused adolescents, especially if they are currently highly distressed by the experience, and regardless of current level of depressive symptomatology. Substance abuse, post-traumatic stress and personality disorders may be co-morbid problems (Brand, King, Olson, Ghaziuddin, \& Naylor, 1996); however they should be addressed in conjunction with the abuse.

We believe this study confirms that the effects of sexual abuse for boys are not less serious or harmful than for girls; quite possibly effects and their implications are more serious. Although there are difficulties in the detection of CSA (Maddocks, Griffiths, \& Antao, 1999), and in the prediction of suicide risk in a clinical setting (Joiner, Rudd, \& Rajab, 1999), all professionals in contact with adolescents need to be aware of the strong relationship between the experience of CSA and high risk suicidal behavior.

\section{References}

Allison, S., Roeger, L., Martin, G., \& Keeves, J. (2001). Gender differences in the relationship between depression and suicidal ideation in young adolescents. Australian and New Zealand Journal of Psychiatry, 35, 498-503.

Barker Collo, S. (2001). Adult reports of child and adult attributions of blame for childhood sexual abuse: Predicting adult adjustment and suicidal behaviors in females. Child Abuse \& Neglect, 25(10), 1329-1341.

Beautrais, A. L. (2000). Risk factors for suicide and attempted suicide among young people. Australian and New Zealand Journal of Psychiatry, 34(3), 420-436.

Beck, A. T., Weissman, A., Lester, D., \& Trexler, L. (1974). The measurement of pessimism: The Hopelessness Scale. Journal of Consulting and Clinical Psychology, 42(6), 861-865.

Beckinsale, P., Martin, G., \& Clark, S. (1999). Sexual abuse and suicidal issues in Australian young people: An interim report. Australian Family Physician, 28(12), 1298-1303.

Beitchman, J. H., Zucker, K. J., Hood, J. E., daCosta, G. A., \& Akman, D. (1991). A review of the short-term effects of child sexual abuse. Child Abuse \& Neglect, 15(4), 537-556.

Bensley, L. S., Van Eenwyk, J., Spieker, S. J., \& Schoder, M. N. (1999). Self-reported abuse history and adolescent problem behaviours. I. Antisocial and suicidal behaviors. Journal of Adolescent Health, 24, 163-172.

Bergen, H. A., Martin, G., Richardson, A. S., Allison, S., \& Roeger, L. (2003). Sexual abuse and suicidal behavior: A model constructed from a large community sample of adolescents. Journal of the American Academy of Child and Adolescent Psychiatry, 42(11), 1301-1309.

Brand, E. F., King, C. A., Olson, E., Ghaziuddin, N., \& Naylor, M. (1996). Depressed adolescents with a history of sexual abuse: Diagnostic comorbidity and suicidality. Journal of the American Academy of Child and Adolescent Psychiatry, 35(1), 34-41.

Broussard, S., Wagner, W. G., \& Kazelskis, R. (1991). Undergraduate students' perceptions of child sexual abuse: The impact of victim sex, perpetrator sex, respondent sex, and victim response. Journal of Family Violence, 6(3), 267-278.

Brown, J., Cohen, P., Johnson, J. G., \& Smailes, E. M. (1999). Childhood abuse and neglect: Specificity and effects on adolescent and young adult depression and suicidality. Journal of the American Academy of Child and Adolescent Psychiatry, 38(12), 1490-1496.

Byles, J., Byrne, C., Boyle, M., \& Offord, D. R. (1988). Ontario Child Health Study: Reliability and validity of the general functioning subscale of the McMaster family assessment device. Family Process, 27, 97-104.

Calam, R., Horne, L., Glasgow, D., \& Cox, A. (1998). Psychological disturbance and child sexual abuse: A follow-up study. Child Abuse \& Neglect, 22(9), 901-913.

Corbett, K., Gentry, C. S., \& Pearson, W. (1993). Sexual harassment in high school. Youth and Society, 25(1), 93-103. 
Farrington, D. P., \& Loeber, R. (2000). Some benefits of dichotomization in psychiatric and criminological research. Criminal Behaviour and Mental Health, 10(2), 100-122.

Fergusson, D. M., Lynskey, M. T., \& Horwood, L. J. (1996). Childhood sexual abuse and psychiatric disorder in young adulthood: I. Prevalence of sexual abuse and factors associated with sexual abuse. Journal of the American Academy of Child and Adolescent Psychiatry, 35(10), 1355-1364.

Garnefski, N., \& Arends, E. (1998). Sexual abuse and adolescent maladjustment: Differences between male and female victims. Journal of Adolescence, 21(1), 99-107.

Garson, G. D. (2002). Logistic regression. PA 765 statnotes: An online textbook. Retrieved September 17th from http://www2.chass.ncsu/garson/pa765/logistic.htm.

Gibb, B. E., Alloy, L. B., Abramson, L. Y., Rose, D. T., Whitehouse, W. G., \& Hogan, M. E. (2001). Childhood maltreatment and college students' current suicidal ideation: A test of the hopelessness theory. Suicide and Life Threatening Behavior, 31(4), 405-415.

Goldman, J. D. G., \& Padayachi, U. K. (1997). The prevalence and nature of child sexual abuse in Queensland. Australia Child Abuse \& Neglect, 21(5), 489-498.

Joiner, T. E., Jr., Rudd, M. D., \& Rajab, M. H. (1999). Agreement between self- and clinician-rated suicidal symptoms in a clinical sample of young adults: Explaining discrepancies. Journal of Consulting and Clinical Psychology, 67(2), 171-176.

Klimes Dougan, B. (1998). Screening for suicidal ideation in children and adolescents: Methodological considerations. Journal of Adolescence, 21(4), 435-444.

Lewinsohn, P. M., Rohde, P., Seeley, J. R., \& Baldwin, C. L. (2001). Gender differences in suicide attempts from adolescence to young adulthood. Journal of the American Academy of Child and Adolescent Psychiatry, 40(4), 427-434.

Lipschitz, D. S., Winegar, R. K., Nicolaou, A. L., Hartnick, E., Wolfson, M., \& Southwick, S. M. (1999). Perceived abuse and neglect as risk factors for suicidal behavior in adolescent inpatients. Journal of Nervous and Mental Disease, 187(1), 32-39.

Loredo, C., Reid, A., \& Deaux, K. (1995). Judgments and definitions of sexual harassment by high school students. Sex Roles, $32(1 / 2), 29-45$.

Maddocks, A., Griffiths, L., \& Antao, V. (1999). Detecting child sexual abuse in general practice: A retrospective case-control study from Wales. Scandinavian Journal of Primary Health Care, 17(4), 210-214.

Martin, G. (1996). Reported family dynamics, sexual abuse and suicidal behaviors in community adolescents. Archives of Suicide Research, 2(3), 183-195.

Martin, G., Allison, S., Pearce, C., Cornelissen, S., Rafferty, S., Mead, P., \& Williams, K. (1995). Early detection of emotional disorder with particular reference to suicidal behaviours: A preliminary report. In B. Singh \& F. Judd (Eds.), 17th Geigy psychiatric symposium: Suicide (pp. 27-45). Melbourne, Australia: CIBA-Geigy.

Martin, G., Rozanes, P., Pearce, C., \& Allison, S. (1995). Adolescent suicide, depression and family dysfunction. Acta Psychiatrica Scandinavica, 92, 336-344.

Mazza, J. J., \& Reynolds, W. M. (1998). A longitudinal investigation of depression, hopelessness, social support, and major and minor life events and their relation to suicidal ideation in adolescents. Suicide and Life Threatening Behavior, 28(4), 358-374.

Molnar, B. E., Berkman, L. F., \& Buka, S. L. (2001). Psychopathology, childhood sexual abuse and other childhood adversities: Relative links to subsequent suicidal behaviour in the US. Psychological Medicine, 31(6), 965-977.

Mullen, P. E., King, N. J., \& Tonge, B. J. (2000). Child sexual abuse: An overview. Behaviour Change, 17(1), 2-14.

Mullen, P. E., Martin, J. L., Anderson, J. C., Romans, S. E., \& Herbison, G. P. (1996). The long-term impact of the physical, emotional, and sexual abuse of children: A community study. Child Abuse \& Neglect, 20(1), 7-21.

Nelson, E. C., Heath, A. C., Madden, P. A. F., Cooper, L., Dinwiddie, S. H., Bucholz, K. K., Glowinski, A., McLaughlin, T., Dunne, M. P., Statham, D. J., \& Martin, N. G. (2002). Association between self-reported childhood sexual abuse and adverse psychosocial outcomes: Results from a twin study. Archives of General Psychiatry, 59(2), 139-145.

Paolucci, E. O., Genuis, M. L., \& Violato, C. (2001). A meta-analysis of the published research on the effects of child sexual abuse. Journal of Psychology, 135(1), 17-36.

Pearce, C. M., \& Martin, G. (1994). Predicting suicide attempts among adolescents. Acta Psychiatrica Scandinavica, 90(5), 324-328.

Pfeffer, C. R., Klerman, G. L., Hurt, S. W., Lesser, M., Peskin, J. R., \& Siefker, C. A. (1991). Suicidal children grow up: Demographic and clinical risk factors for adolescent suicide attempts. Journal of the American Academy of Child and Adolescent Psychiatry, 30(4), 609-616. 
Pillay, A. L., \& Schoubben Hesk, S. (2001). Depression, anxiety, and hopelessness in sexually abused adolescent girls. Psychological Reports, 88(3), 727-733.

Prinstein, M. J., Nock, M. K., Spirito, A., \& Grapentine, W. L. (2001). Multimethod assessment of suicidality in adolescent psychiatric inpatients: Preliminary results. Journal of the American Academy of Child and Adolescent Psychiatry, 40(9), 1053-1061.

Radloff, L. S. (1977). The CES-D scale: A self-report depression scale for research in the general population. Applied Psychological Measurement, 1(3), 385-401.

Radloff, L. S. (1991). The use of the Center for Epidemiologic Studies Depression Scale in adolescents and young adults. Journal of Youth and Adolescence, 20(2), 149-166.

Rich, A. R., Kirkpatrick Smith, J., Bonner, R. L., \& Jans, F. (1992). Gender differences in the psychosocial correlates of suicidal ideation among adolescents. Suicide and Life Threatening Behavior, 22(3), 364-373.

Roberts, R. E., Andrews, J. A., Lewinsohn, P. M., \& Hops, H. (1990). Assessment of depression in adolescents using the Center for Epidemiologic Studies Depression Scale. Psychological Assessment, 2(2), 122-128.

Romans, S., Martin, J., \& Mullen, P. (1997). Childhood sexual abuse and later psychological problems: Neither necessary, sufficient nor acting alone. Criminal Behaviour and Mental Health, 7(4), 327-338.

Silverman, A. B., Reinherz, H. Z., \& Giaconia, R. M. (1996). The long-term sequelae of child and adolescent abuse: A longitudinal community study. Child Abuse \& Neglect, 20(8), 709-723.

Smith, H. D., Fromuth, M. E., \& Morris, C. C. (1997). Effects of gender on perceptions of child sexual abuse. Journal of Child Sexual Abuse, 6(4), 51-60.

Stevenson, J. (1999). The treatment of the long-term sequelae of child abuse. Journal of Child Psychology and Psychiatry and Allied Disciplines, 40(1), 89-111.

Tabachnick, B. G., \& Fidell, L. S. (2001). Using multivariate statistics (4th ed.). Needham Heights, MA: Allyn and Bacon.

Tyler, K. A. (2002). Social and emotional outcomes of childhood sexual abuse: A review of recent research. Aggression and Violent Behavior, 7(6), 567-589.

\section{Résumé}

Objectif: Une étude selon le genre sur un échantillon d'adolescents représentatif d'une population d'une communauté sur les relations entre les abus sexuels subis dans l'enfance spontanément révélés et la problématique concernant le suicide.

Méthode: Les étudiants âgés en moyenne de 14 ans $(N=2,485)$ de 27 écoles du Sud de l'Australie ont rempli un questionnaire comportant des items sur les abus sexuels et la tendance au suicide, avec des mesures de la dépression (Centre for Epidemiological Studies Depression Scale), le désespoir (Beck Hopelessness Scale), et le fonctionnement de la famille (McMaster Family Assessment Device general Functioning Subscale). L'analyse des données a comporté une régression logistique.

Résultats: Chez les garçons les abus sexuels spontanément révélés sont fortement et indépendamment associés à des idées de suicide, des projets, des menaces, des blessures volontaires et des tentatives de suicide, après contrôle d'un niveau actuel de dépression, du désespoir et du disfonctionnement familial. Chez les filles, la relation entre abus sexuels et tendance au suicide est influencée entièrement par la dépression, le désespoir et le disfonctionnement familial. Les filles qui rapportent une grande détresse actuelle concernant un abus sexuel courent toutefois 3 fois plus de risques de faire des projets et des menaces de suicide que les filles non-abusées. Les garçons qui rapportent un haut niveau de détresse actuelle concernant un abus sexuel courent un risque 10 fois plus grand de faire des projets et des menaces de suicide que les garçons non-abusés. 55\% $(n=15)$ des garçons abusés ont fait une tentive de suicide contre $29 \%(n=17)$ des filles.

Conclusions: La mention d'abus sexuels subis devrait alerter les cliniciens, les professionnels ainsi que ceux qui dispensent des soins à des adolescents:les garçons, même s'ils ne semblent pas déprimés ou 
découragés peuvent courir de grands risques de présenter des comportements suicidaires ou de faire des tentatives de suicide. La détresse suivant un abus sexuel, jointe à la dépression et au découragement signale un risque accru de comportement suicidaire autant chez les filles que chez les garçons.

\section{Resumen}

Spanish language abstract not available at time of publication. 